\title{
Studies on Mechanisms of Antinephritic Action of SA-446, an Angiotensin I Converting Enzyme Inhibitor (1) A Comparison with Actions of Spironolactone, Kallidinogenase and Saralacin
}

\author{
Yoshio SUZUKI, Mikio ITO and Naoto SAITO \\ Department of Pharmacology, Faculty of Pharmacy, Meijo University. \\ Tenpaku-ku, Nagoya 468. Japan
}

Accepted August 18, 1986

\begin{abstract}
The present study was made to clarify the mechanisms of the antinephritic action of SA-446, an angiotensin I canverting enzyme inhibitor, on crescentic-type anti-GBM nephritis in rats as compared to the actions of spironolactone (an antialdosterone agent), kallidinogenase (a kallikrein agent) and saralasin (an angiotensin II antagonist). SA-446 (25 mg/ $/ \mathrm{kg} /$ day, p.o.) had a tendency to reduce the urinary protein excretion and plasma urea nitrogen content. In addition. this drug remarkably inhibited not only glomerular histopathological changes (i.e., crescent formation, the adhesion of capillary walls to Bowman's capsule and fibrinoid necrosis) but also the elevation of blood pressure. Spironolactone (25 mg/kg/day, p.o.) and kallidinogenase (25 KU/day, i.m.) also showed beneficial effects on glomerular histopathological changes and hypertension. although both drugs were not as effective as SA-446. However, saralasin (72 $\mu \mathrm{g} /$ day. s.c.) caused a marked aggravating action on this nephritis. This nephritic model showed a marked low activity of plasma renin all through the 40 day experimental period. In this model, the urinary aldosterone excretion was increased, in spite of the decrease in plasma renin activity. SA-446 and kallidinogenase significantly inhibited the decrease in plasma renin activity and the increase in urinary aldosterone excretion. Spironolactone inhibited only the increase in the aldosterone excretion. However, saralasin decreased the plasma renin activity under the control level and strongly increased the urinary aldosterone excretion (about 1.8 times the control level on the 20th day). These results suggest that the antinephritic effect of SA-446 may be related to the antihypertensive action and the increase in renal blood flow through activation of the kallikrein-kinin and prostaglandins systems.
\end{abstract}

In recent years, it has been demonstrated that an angiotensin I converting enzyme (ACE) inhibitor, a new type of hypotensive agent, reduces the blood pressure in renovascular hypertension as well as essential hypertension (1). It has been speculated that the hypotensive action of ACE inhibitors may be caused by inhibition of the conversion of angiotensin $\mid$ to angiotensin || and/or by inhibition of the destruction of kinins, the potent vasodepressors (2-4). We have already reported that a positive correlation exists between the crescent formation in glomeruli and the blood pressure in crescentic-type anti-glomerular basement membrane (anti-GBM) nephritis of rats and that SA-446 [(2R, 4R)-2-(2-hydroxyphenyl)3-(3-mercaptopropionyl)-4-thiazolidinecarboxylic acid], an ACE inhibitor, shows beneficial effects on histopathological changes in glomeruli and hypertension (5). This result suggests that either the reninangiotensin-aldosterone or kallikrein-kinin (K-K) system may be related to the pro- 
gression of glomerular histopathological changes and the elevation of blood pressure in this nephritic model. In the present study, the mechanisms of antinephritic action of SA-446 were investigated by comparing the actions of spironolactone, an antialdosterone agent: kallidinogenase, a kallikrein agent; and saralasin, an angiotensin II antagonist.

\section{Materials and Methods}

Animals: Male Sprague-Dawley strain rats weighing approx. $190 \mathrm{~g}$ (Keari Chubu Branch Office) were used. These animals were housed in an air-conditioned room at $23 \pm 1^{\circ} \mathrm{C}$

Drugs: Drugs used were SA-446 (Santen Pharmaceutical. Co.), spironolactone (Dainippon Pharmaceutical. Co.), saralasin (Peptide Research Laboratory) and kallidinogenase [Depo-Kallikrein] (Bayer Co.) Both SA-446 and spironolactone were suspended in $0.5 \%$ gum arabic. Saralasin and kallidinogenase were dissolved in $0.9 \%$ saline and $10 \%$ polyvinylpyrrolidine, respectively.

Induction of nephritis and drug administration: In experiment I, crescentic-type antiGBM nephritis was induced in rats by a slight modification of the method reported previously (5). The rats were injected with $0.5 \mathrm{ml}$ of rabbit anti-rat GBM serum (antiGBM serum)/animal into the tail vein. On the day after the anti-GBM serum injection. $24 \mathrm{hr}$ urine samples were collected, and the rats were then divided into three groups $(n=8)$. so that the average protein content in the $24 \mathrm{hr}$ urine sample of each group was at the same level. After grouping, these animals were injected with $5 \mathrm{mg}$ of rabbit $\gamma$-globulin in $0.25 \mathrm{ml}$ of Freund's complete adjuvant into the hind foot-pads. Two groups were given p.o. daily $25 \mathrm{mg} / \mathrm{kg}$ of SA-446 and spironolactone from the day of rabbit $\gamma$ globulin injection (the 2 nd day) to the 39 th day. The remaining group was given vehicle ( $0.5 \%$ gum arabic, p.0., daily) as the control. In experiment 11 , nephritic rats were divided into three groups $(n=7)$. Two groups were used for test drugs. One group was given 25 KU of kallidinogenase/animal, i.m., daily. and the other group was injected s.c. continually with $72 \mu \mathrm{g} /$ day $(50 \mu \mathrm{g} / \mathrm{min})$ of saralasin with a mini-osmotic pump for the same period as in experiment 1 . The remaining group was given the vehicle $(0.9 \% \mathrm{NaCl}$, i.m., daily) as the control.

Collections of urine, blood and kidneys: The $24 \mathrm{hr}$ urine samples were collected on the $1 \mathrm{st}, 5$ th, 10th, 20th, 30th and 40th days after the injection of anti-GBM serum. Blood was drawn in a volume of $0.5 \mathrm{ml}$ from the tail vein on day 0 and the 7 th, 21 st and 38 th days. On the 40 th day, whole blood was taken from the abdominal aorta. In the case of the urine collection, each animal received $5 \mathrm{ml}$ of distilled water twice orally without feeding at the beginning and $5 \mathrm{hr}$ after the collection. The $24 \mathrm{hr}$ urine samples were obtained by keeping each animal in individual metabolic cages. The urine obtained was then centrifuged at $3.000 \mathrm{rpm}$ for $10 \mathrm{~min}$ at $4^{\circ} \mathrm{C}$, and the supernatant was used for the determinations. In the case of blood collection. blood was taken in centrifuge tubes containing $1 \mathrm{mg}$ of EDTA-2 $\mathrm{Na}(1-5 \%$ solution in $0.9 \% \mathrm{NaCl}) / \mathrm{ml}$ of blood. The blood was then centrifuged at $3.000 \mathrm{rpm}$ for $10 \mathrm{~min}$ at $4^{\circ} \mathrm{C}$ to obtain plasma. After whole blood collections on the 40th day, both kidneys were taken for histopathological studies.

Determinations of urinary protein and plasma urea nitrogen contents: The urinary protein content was determined by the method of Kingsbury et al. (6) and expressed as $\mathrm{mg} / 24 \mathrm{hr}$ urine. The plasma urea nitrogen content was determined in accordance with the method of Searcy and Cox (7) and expressed as $\mathrm{mg} / \mathrm{dl}$ of plasma.

Determinations of plasma renin activity and urinary aldosterone contents: The plasma renin activity was determined with a commercial kit [RENCTK] (Midori Juji) by radioimmunoassay (8) and expressed as $\mathrm{ng}$ angiotensin I ( $\mathrm{Ag} \mathrm{l}) / \mathrm{ml}$ of plasma/hr. The urinary aldosterone content was determined with an aldosterone. $1-125$ kit [ALDOCTK125] (Midori Juji) by radioimmunoassay (9) and expressed as $\mathrm{ng} / 24 \mathrm{hr}$ urine.

Measurement of blood pressure: Blood pressure was measured by a tail plethysmography [KN-209] (Natsume) on day 0 and the 7th, 14th, 21st, 28th and 38th days.

Assessment of histopathological parameters: For light microscopic study, kidneys were dehydrated and fixed by immersing the tissues stepwise into low to high concen- 
trations of alcohol. The tissues were then embedded in paraffin and sectioned $2-3 \mu \mathrm{m}$ thick. The sections were stained with hematoxylin and eosin and Masson trichrome. As histopathological parameters in the glomeruli. crescent formation, adhesion of capillary walls to Bowman's capsule (adhesion) and fibrinoid necrosis were observed in fifty glomeruli per section under light microscopy. The degree of changes in these three histopathological parameters was scored as: mild (1). moderate (2) and severe (3). The number of glomeruli corresponding to each score was represented as $n_{1}, n_{2}$ and $n_{3}$. The crescent formation index $(\mathrm{Cl})$, the adhesion index (Al) and the fibrinoid necrosis index $(F I)$ were calculated by the following formula: $\mathrm{Cl}$. $\mathrm{Al}$ and $\mathrm{FI}=1 \times n_{1}+2 \times n_{2}+3 \times n_{3}$. The degree of glomerular lesions was expressed as the index of glomerular lesions (IGL) and calculated by the following formula:

$$
=\frac{(3 \times \mathrm{Cl})+(2 \times \mathrm{Al})+(1 \times \mathrm{FI})}{(3+2+1) \times 50}
$$

Statistical analysis: The data are given as the mean \pm S.E., and the results were statistically evaluated by Student's $t$-test.

\section{Results}

1. Effects on urinary protein excretion and plasma urea nitrogen level (Fig. 1)

SA-446 and spironolactone: SA-446 (25 $\mathrm{mg} / \mathrm{kg} /$ day, $p$ o.) significantly inhibited the urinary protein excretion by $30.8 \%$ on the 10 th day and then tended to inhibit it up to

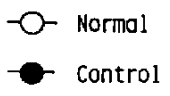

Urinary protein

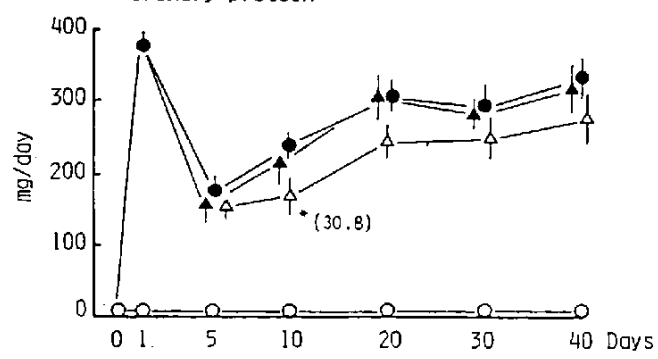

$\triangle$ SA-446 $25 \mathrm{mg} / \mathrm{kg} /$ day p.0.

Splronolactone $25 \mathrm{mg} / \mathrm{kg} /$ doy $\mathrm{p}, 0$.

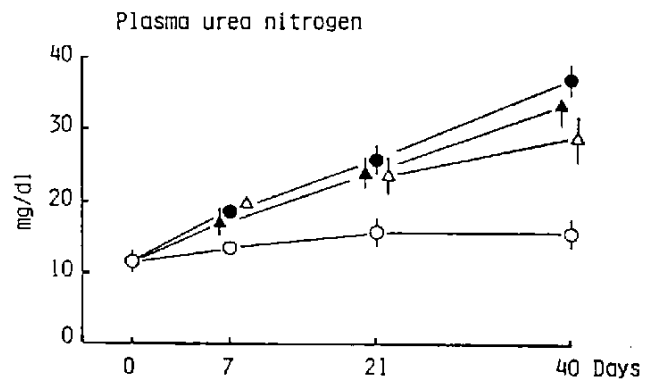

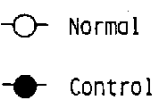

Ur!nary protein

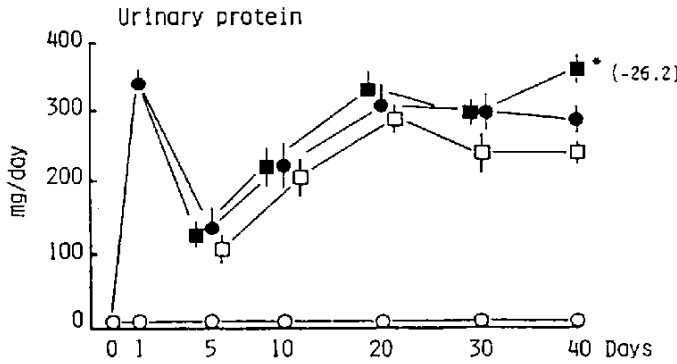

Kallidinogenase $25 \mathrm{kU} / \mathrm{day} 1 . \mathrm{m}$.

Saralasin $72 \mathrm{wg} /$ day s.c.

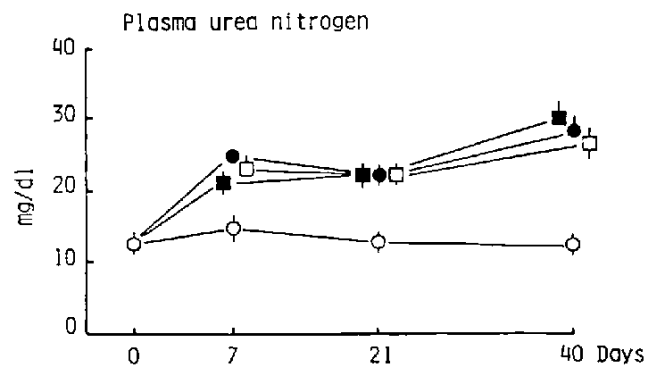

Fig. 1. Effects of SA-446, spironolactone, kallidinogenase and saralasin on urinary protein excretion and plasma urea nitrogen content in crescentic-type anti-GBM nephritis in rats. Each plot denotes the mean value with S.E. of 7 or 8 rats. The number in parenthesis indicates the percent inhibition which was derived from the following formula: $\frac{C-T}{C-N} \times 100(C$ : Control, T: Test drug. N: Normal). *indicates a significant difference from the control at $P<0.05$. 


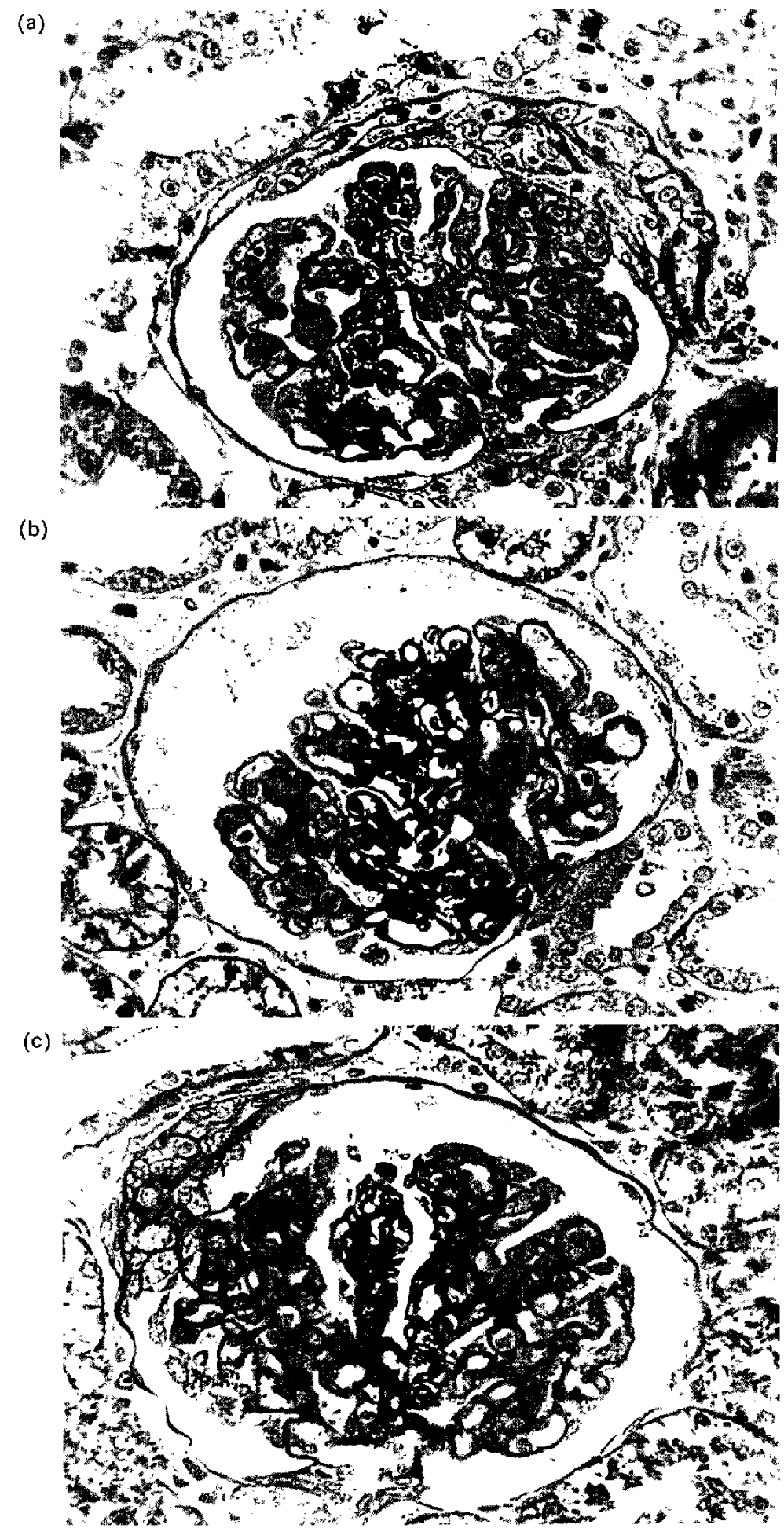

Photo 1. Kidney sections from control (a), SA-446, $25 \mathrm{mg} / \mathrm{kg} /$ day, p.o.-treated (b) and spironolactone, $25 \mathrm{mg} / \mathrm{kg} /$ day, p.o.-treated (c) rats on the 40 th day after injection of anti-GBM serum. Masson trichrome stain $(\times 200)$. 
(a)

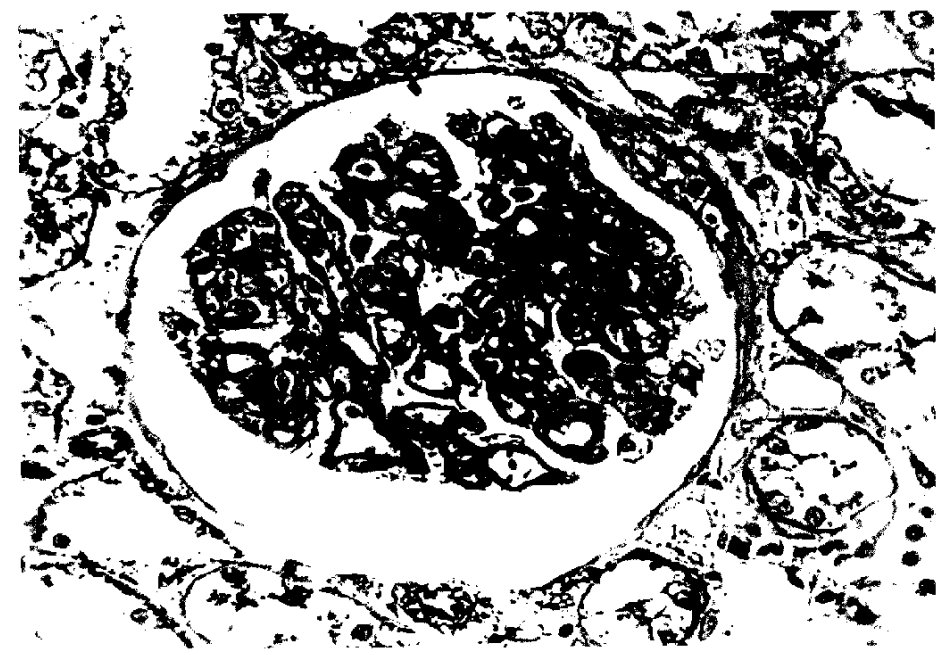

(b)

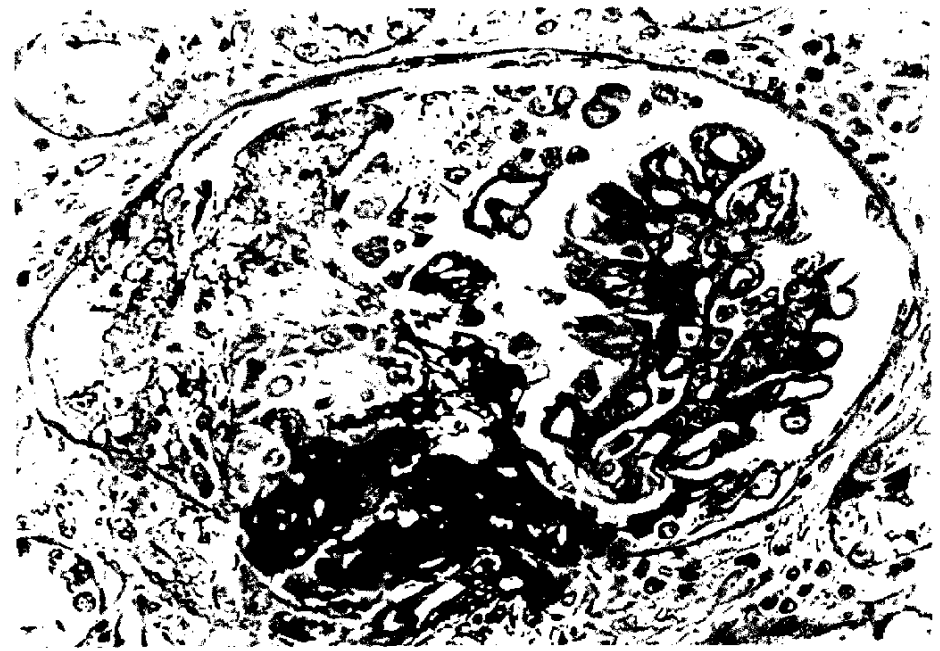

Photo 2. Kidney sections from kallidinogenase, $25 \mathrm{KU} /$ day, p.o.-treated (a) and saralasin, $72 \mu \mathrm{g} /$ day, s.c.-treated (b) rats on the 40 th day after injection of anti-GBM serum. Masson trichrome stain $(\times 200)$.

the 40th day. In addition, this drug showed a tendency to reduce the plasma urea nitrogen levels on the 40th day. On the other hand. spironolactone $(25 \mathrm{mg} / \mathrm{kg} /$ day. p.o.) was ineffective in reducing both parameters.

Kallidinogenase and saralasin: Kallidinogenase ( $25 \mathrm{KU} /$ day, i.m.) did not affect the urinary protein excretion and the plasma urea nitrogen level. On the other hand, saralsain (72 $\mu \mathrm{g} /$ day, s.c.) caused a significant increase of $26 \%$ on the protein excretion on the 40 th day.

2. Effects on histopathological parameters in glomeruli (Fig. 2)

SA-446 and spironolactone: In the histo- pathological assessment on the 40th day. SA-446 (25 mg/ $\mathrm{kg} /$ day, p.o.) remarkably reduced the $\mathrm{Cl}$, the $\mathrm{Al}$ and the $\mathrm{FI}$ by $50.3 \%$. $53.4 \%$ and $56.5 \%$, respectively. Spironolactone $(25 \mathrm{mg} / \mathrm{kg} /$ day, p.o.) also significantly reduced the indices of these three histopathological parameters by about $40 \%$. SA446 and spironolactone reduced the IGL calculated on the basis of these three parameters by $52.0 \%$ and $35.7 \%$, respectively. Representative micrographs of glomeruli from rats treated with both drugs are given in Photo 1.

Kallidinogenase and saralasin: Kallidinogenase (25 KU/day, i.m.) was as effective as 
Control $\square$ SA-445 $25 \mathrm{mg} / \mathrm{kg} / \mathrm{doy} 0.0$. IIIIll SDlronolactone $25 \mathrm{mg} / \mathrm{kg} / \mathrm{dor}$ 0.0.
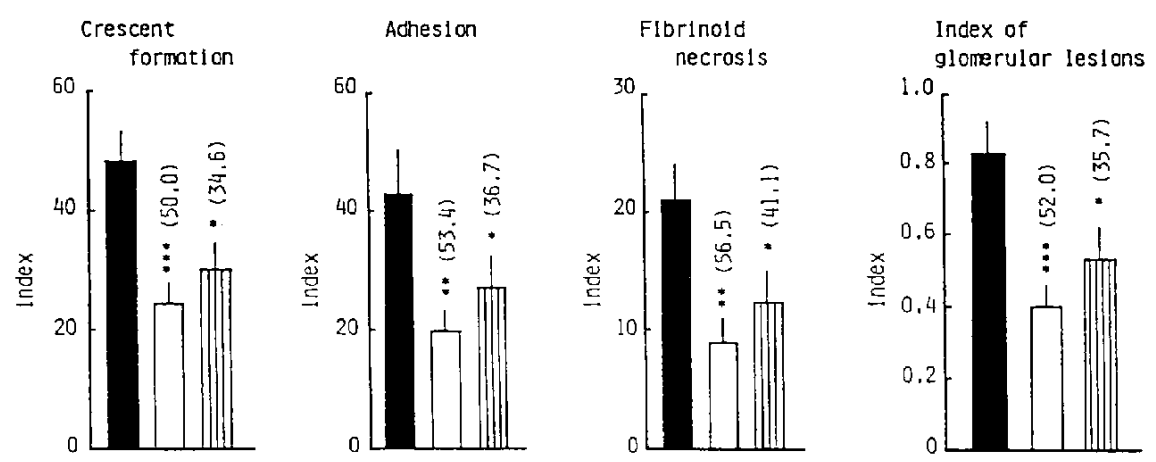

Control Kallidinogenose $25 \mathrm{~kJ} / \mathrm{doy}$ i.m.

Za sorolas In $72 \mu g / d a y s . c$.
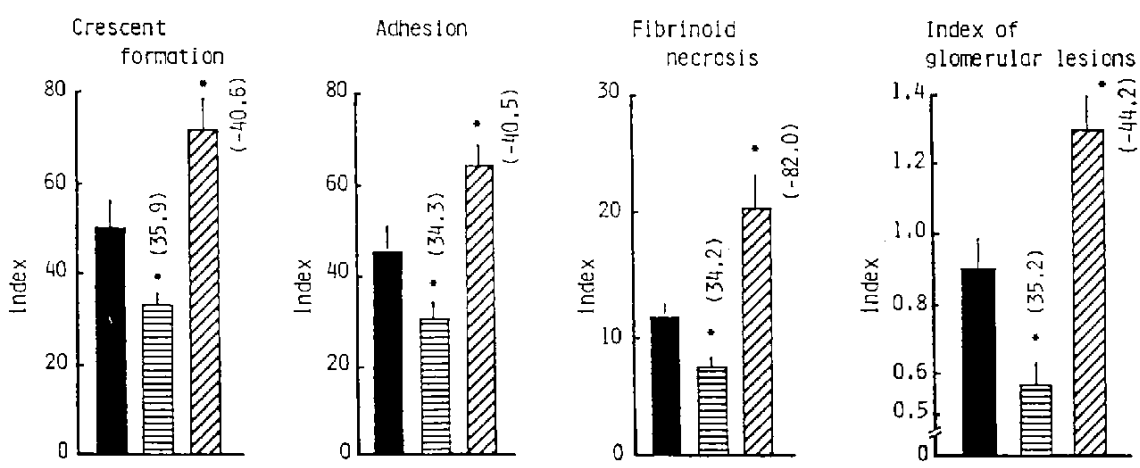

Fig. 2. Effects of SA-446. spironolactone. kallidinogenase and saralasin on histopathological parameters in glomeruli on the 40th day after injection of anti-GBM serum in crescentic-type anti-GBM nephritis in rats. Each column denotes the mean \pm S.E. of 7 or 8 rats. The number in parenthesis indicates a percent inhibition which was derived from the following formula: $\mathrm{C}_{\mathrm{C}}^{\mathrm{T}} \times 100$ (C: Control. T: Test drug). " * and *** indicate a significant difference from the control at $P<0.05,0.01$ and 0.001 , respectively.

spironolactone on histopathological parameters. However, saralasin (72 $\mu \mathrm{g} /$ day, s.c.) significantly increased the $\mathrm{Cl}$, the $\mathrm{Al}$ and the $\mathrm{FI}$ by $40.6 \%, 40.5 \%$ and $82.0 \%$, respectively. Thus, only saralasin caused an undesirable effect histopathologically. Photo 2 indicates representative micrographs of glomeruli from rats given both drugs.

3. Effects on blood pressure (Fig. 3)

SA-446 and spironolactone: SA-446 (25 $\mathrm{mg} / \mathrm{kg} / \mathrm{day}$, p.o.) pronouncedly inhibited the elevation of blood pressure by $42.0 \%-65.6 \%$ from the 7 th to the 30th days. Spironolactone ( $25 \mathrm{mg} / \mathrm{kg} /$ day, p.o.) also showed an antihypertensive effect for the same foriods, but the effect was inferior to that of SA-446.

Kallidinogenase and saralasin: Kallidinogenase $(25 \mathrm{KU} /$ day, i.m. $)$ was also as potent as SA-446 in lowering the blood pressure. However, saralasin (72 $\mu \mathrm{g} /$ day, s.c.) markedly elevated the blood pressure over that of the control on the 38th day.

4. Effects on plasma ranin activity and urinary aldosterone excretion (Fig. 4)

SA-446 and spironolactone: The plasma renin activity of the control group showed a markedly low level as compared with that of the normal group on the 7 th day $(0.69 \pm 0.1$ ng $\mathrm{Ag} \mathrm{l} / \mathrm{ml} / \mathrm{hr}$ vs. $8.31 \pm 1.45 \mathrm{ng} \mathrm{Ag} \mathrm{l} / \mathrm{ml} / \mathrm{hr}$ ). Thereafter, the low level of plasma renin 

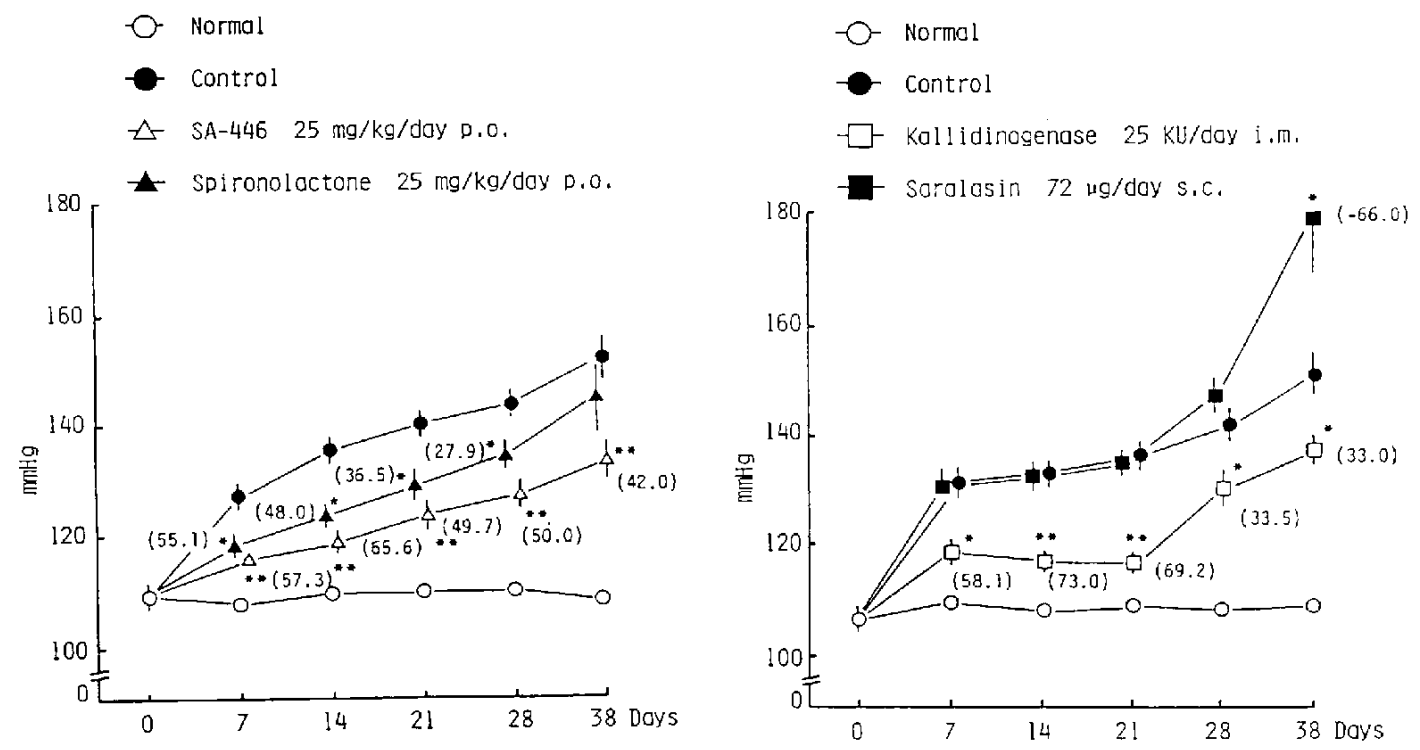

Fig. 3. Effects of SA-446, spironolactone, kallidinogenase and saralasin on blood pressure in crescentictype anti-GBM nephritis in rats. Each plot denotes the mean value with S.E. of 7 or 8 rats. The number in parenthesis indicates the percent inhibition which was derived from the following formula: $\frac{C-T}{C-N}$ $\times 100$ ( $\mathrm{C}$ : Control, T: Test drug. N: Normal). * and ** indicate a significant difference from the control at $P<0.05$ and 0.01 , respectively.

activity of the control group remained unchanged by the 38th day. SA-446 (25 $\mathrm{mg} / \mathrm{kg} /$ day, p.o.) caused a significant inhibition of $46.8 \%$ on the marked lowering of plasma renin activity on the 38 th day. However, the renin activity was little affected by spironolactone $(25 \mathrm{mg} / \mathrm{kg} /$ day, p.o.). The urinary aldosterone excretion of the control group was significantly high as compared with that of the normal group on the 1 st day

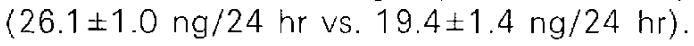
Later, the aldosterone excretion continued to increase up to the 20th day with the level decreasing slightly on the 40th day. The marked increase in urinary aldosterone excretion was significantly inhibited $77.0 \%$ and $89.6 \%$ by SA-446 and spironolactone on the 20th day, respectively.

Kallidinogenase and saralasin: Like SA446. kallidinogenase (25 KU/day, i.m.) significantly inhibited the lowering of plasma renin activity by $33.0 \%$ on the 38 th day and the increase in urinary aldosterone excretion by $57.9 \%$ on the 40 th day. However, saralasin (72 $\mu \mathrm{g} /$ day, s.c.) significantly decreased the renin activity by $12.6 \%$ and $23.5 \%$ on the 21 st and 38 th days, respectively. as compared to the control level. In addition, this agent markedly increased the aldosterone excretion by 1.8 and 1.5 times the control levels on the 20th and 40th days, respectively.

\section{Discussion}

The present study confirmed that SA-446 (25 mg/kg/day, p.o.), an ACE inhibitor, has a very beneficial effect on histopathological changes in glomeruli and hypertension of crescentic-type anti-GBM nephritis in rats, although it had only a very weak inhibitory effect on urinary protein excretion. In general, there is no correlation between renal histological findings and proteinuria of glomerulonephritis. We previously found that there was a close relationship between glomerular lesions and blood pressure in this model (5). It has been generally considered that the prognosis of patients with hypertensive-type nephritis is incurable as compared with that of patients with normotensive nephritis. Tikkanen et al. (10) demonstrated 

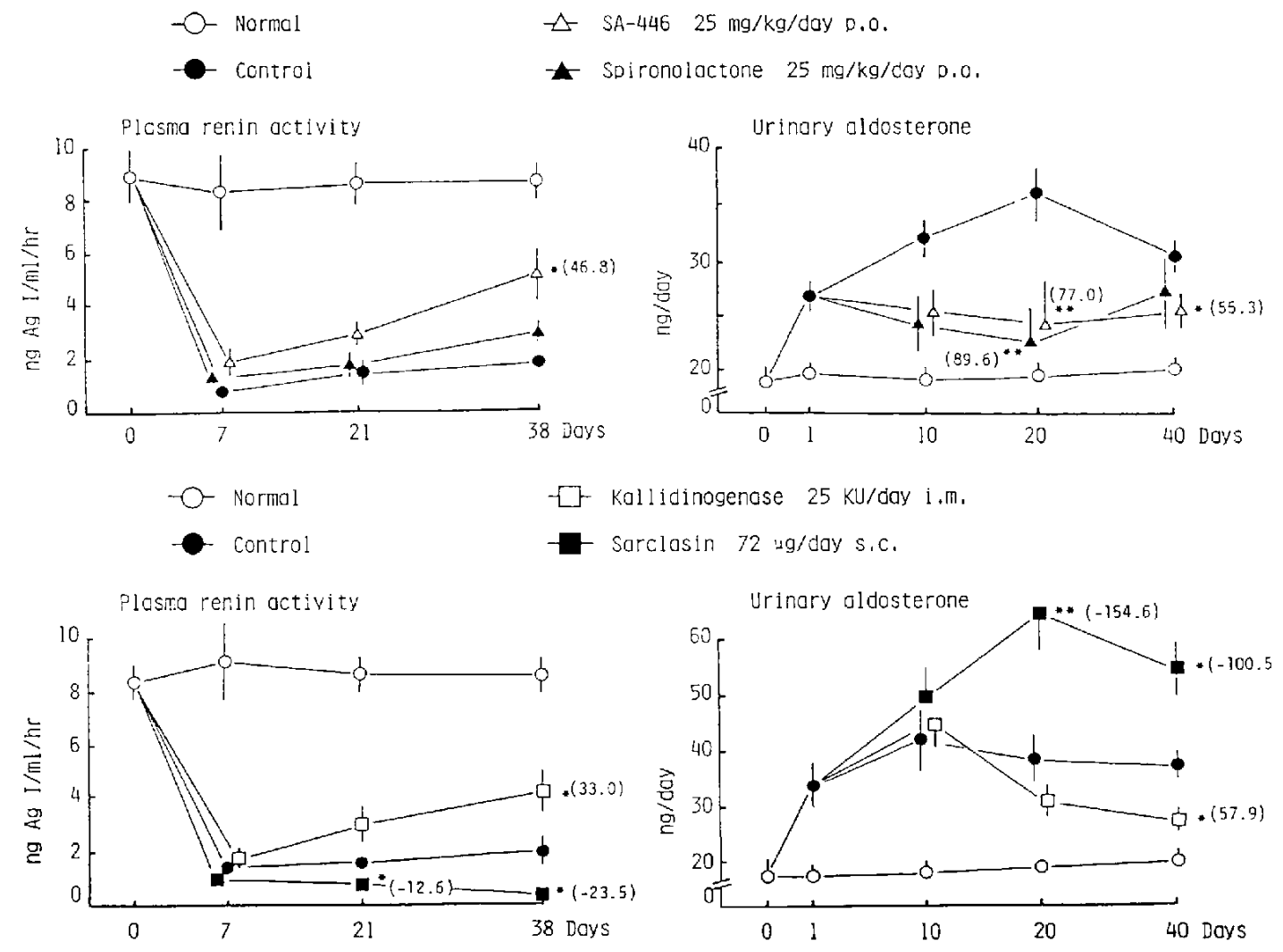

Fig. 4. Effects of SA-446, spironolactone, kallidinogenase and saralasin on plasma renin activity and urinary aldosterone excretion in crescentic-type anti-GBM nephritis in rats. Each plot denotes the mean value with S.E. of 7 or 8 rats. The number in parenthesis indicates the percent inhibition which was derived from the following fourmula: ${ }^{C-T}-\mathrm{N} \times 100\left(\mathrm{C}\right.$ : Control. T: Test drug. N: Normal). ${ }^{*}$ and ** indicate a significant difference from the control at $P<0.05$ and 0.01 , respectively.

experimentally that DOCA- $\mathrm{NaCl}$-treated nephritic rats had a heavier proteinuria and more marked renal lesions than $\mathrm{NaCl}$-treated nephritic rats. Nishio et al. (11) also reported that DOCA- NaCl-treated rats injected i.v. with anti-GBM serum caused more marked glomerular lesions and more severe hypertension than only DOCA- $\mathrm{NaCl}$-treated rats. These results suggest that nephritis and hypertension may closely act as an aggravating factor to each other. Recently, we reported that nicardipine, a calcium antagonist which has been widely used as a hypotensive agent, was beneficial for preventing the progression of crescentic-type anti-GBM nephritis in rats (12). Therefore, a potent preventive action of SA-446 on histopathological changes in glomeruli may be in great part due to the antihypertensive action. Conversely. histopathological improvement by SA-446 may prevent the elevation of blood pressure.

It has been recognized by Iso et al. (13) that the in vitro inhibitory action of SA-446 on semi-purified ACE obtained from rabbit lung is 4 to 5 times larger than of captopril. In the in vivo assay system, the compound has been also demonstrated to be more potent than captopril in inhibiting the ACE in dogs but not in rats (14). Furthermore, SA446 given orally has been reported to have marked antihypertensive actions not only on two kidney, one-clip renal hypertensive rats, a high renin model of hypertension $(14,15)$, 
but also on adult spontaneously hypertensive rats, a normotensive or low renin model of hypertension (13). In the present experiment. SA 446 resulted in a potent hypertensive action on crescentic-type anti-GBM nephritis in rats, although this model maintained markedly low activity of plasma renin during the experimental periods. These findings suggest that the depressor action of SA-446 on high renin hypertension may be linked to inhibition of the conversion of angiotensin I to angiotensin II. However, the depressor action of this drug on low renin hypertension such as the nephritic model used in the present study cannot be explained by inhibition of the renin-angiotensin (R-A) system. In the present experiment, the antinephritic effect of saralasin, an angiotensin II receptor blockade, was examined to clarify whether or not SA-446 exerts the antinephritic action by inhibiting the R-A system. If the possibility is considered as one of the mechanisms of the antinephritic action of SA-446, saralasin is also expected to be beneficial on this nephritis. However, saralasin (72 $\mu \mathrm{g} /$ day, s.c.) brought about severe glomerular lesions and marked pressor action as compared with the control. This observation indicates that the antinephritic action of SA-446 in this nephritic model is not always attributed to inhibition of the R-A system. Furthermore, saralasin, having a chemical structure similar to that of angiotensin II. may act synergismically with angiotensin II on angiotensin II receptors in this model with a low renin activity in plasma because of the decrease in angiotensin II synthesis. This is a reason why saralasin caused the aggravation of the disease.

In the present nephritic model, a marked increase in urinary aldosterone excretion was observed throughout the experimental period. in spite of plasma renin activity being very low. Therefore, the increase in aldosterone secretion observed may not be mediated by activation of the R-A system. Aldosterone is secreted from the zona glomerulosa of the adrenal cortex. However, no histological abnormality of the adrenal cortex was detectable by light microscopic observation (Y. Suzuki et al., unpublished data). At present, the mechanism by which the aldosterone secretion was increased remains unclear. In the present experiment, we investigated whether or not the increase in the aldosterone secretion may be involved in the progression of this nephritis by administering spironolactone, an antialdosterone agent. Spironolactone $(25 \mathrm{mg} / \mathrm{kg} / \mathrm{day}$, p.o.) histopathologically revealed a beneficial effect, although the effect was inferior to that of SA-446. In addition, both drugs inhibited the increase in urinary aldosterone excretion. These results suggest that the excess of aldosterone secretion may be in part related to the progression of the disease, and the protective effect of spironolactone on this nephritis may be explained by inhibition of aldosterone receptors.

It has been shown by Glasser and Michael (16) that there is a prompt significant decrease in urinary kallikrein excretion in anti-GBM nephritis of rats. Therefore, the decrease in urinary kallikrein excretion is likewise expected in the present nephritic model. It is reported that a positive correlation exists between urinary kallikrein and aldosterone excretion in normotensive subjects (17). These findings suggest that the cause of hypertension of this nephritic model may be related to the decrease in renal kallikrein release, even though the aldosterone secretion is increased.

As ACE is identical with kininase II which degrades bradykinin, a potent vosodilator, to inactive fragments, the ACE inhibitors can mediate the accumulation of endogenous bradykinin due to kininase II inhibition. In addition, bradykinin stimulates prostaglandins synthesis (18). Kondo et al. (19) reported that following oral administration of SA-446 or captopril, the maximal decrease in mean blood pressure correlated with the increase in plasma bradykinin. If SA-446 acts through activation of the $K-K$ and prostaglandins systems, kalikrein agents may be also effective on this nephritis. In the present experiment, kallidinogenase $(25 \mathrm{KU} /$ day, i.m.), a kallikrein agent, showed beneficial effects on histopathological changes in glomeruli and hypertension in this nephritis. Therefore, it is postulated from the above findings that the antihypertensive action of SA-446 on crescentic-type anti-GBM 
nephritis may be mainly attributable to activation of the $K-K$ and prostaglandins systems. SA-446 and kallidinogenase also evoked the elevation of plasma renin activity. This result may be related to activation of the $\mathrm{K}-\mathrm{K}$ and prostaglandins systems with SA-446 or kallidinogenase.

In recent years, it has been considered that intraglomerular coagulation and subsequent decrease in blood flow of small vessels may play an important role in progression of glomerulonephritis $(20,21)$. The accumulation of endogenous bradykinin and the increase in prostaglandins by SA-446 may increase the renal blood flow. It is concluded from these results that the antinephritic effect of SA-446 may be due to the reduction in blood pressure and the increase in renal blood flow through activation of the $K-K$ and prostaglandins systems

\section{References}

1 Gavras, H., Brunner, H.R., Turini, G.A., Kershaw, G.R., Tifft, C.P., Cuttelod, S., Gavras, I., Vukovich, R.A. and McKinstry, D.N.: Antihypertensive effect of the oral angiotensin converting enzyme inhibitor SO 14,225 in man. N. Engl. J. Med. 298, 991-995 (1978)

2 Cushman, D.W. and Ondetti, M.A.: Inhibitors of angiotensin-I converting enzyme for treatment of hypertensin. Biochem. Pharmacol. 29, $1871-$ 1877 (1980)

3 Engel, S.L., Schaeffer, T.R., Gold, B.I. and Rubin, B.: Inhibition of pressor effects of angiotensin I and augmentation of depressor effects of bradykinin by synthetic peptides. Proc. Soc. Exp. Biol. Med. 104, 240-244 (1972)

4 Kida, O.: Acute and chronic effects of captopril on the renin-angiotensin and kallikrein systems affecting blood pressure and natriuresis. Japan. J. Nephrol. 27, 343-352 (1985)

5 Suzuki, Y., Ito, M., Yamada, H., Saito, N. and Tsukushi, Y.: Antinephritic effect of SA-446, an angiotensin I converting enzyme inhibitor, on crescentic-type anti-GBM nephritis in rats. Japan. J. Nephrol. 27, 1485-1493 (1985) (Abs. in English)

6 Kingsbury, F.B., Clark, C.P., Williams, G. and Post, A.L.: The rapid determination of albumin in urine. J. Lab. Clin. Med. 11, 981-989 (1926)

7 Searcy, R.L. and Cox, F.M.: A modified technique for ultramicro estimations of urea nitrogen. Clin. Chim. Acta 8, 810-812 (1963)

8 Harber, E., Koerner, T., Page, L.B., Kliman, B. and Purnode, A.: Application of radioimmunoassay for angiotensin I to the physiologic measurements of plasma renin activity in normal human subjects. J. Clin. Endocrinol. Metab. 29, 1349-1355 (1969)

9 Lee, T.P. and Tan, C.H.: A direct radioimmunoassay for aldosterone in unextracted serum and plasma, Clin. Chem, 27, 2019-2022 (1981)

10 Tikkanen, I., Tornroth, T., Miettinen, A. and Fyhrquist, F.: Heymann nephritis-DOCA-NaCi hypertension in the rat. Role of nephritis, DOCA. $\mathrm{NaCl}$ and vascular lesions in the development of hypertension. Nephron 28, 90-95 (1981)

11 Nishio, I., Motoki, K., Mimamikata, T., Tomobuchi, $Y .$, Kusuyama, $Y$. and Masuyama, $Y_{\text {.: }}$ A relationship between nephritis and hypertension in experimental nephritis and hypertension. Japan. J. Nephrol. 24, 761-763 (1982) (in Japanese)

12 Tsukushi, Y., Ito, M. and Suzuki, Y.: Effects of nicardipine on crescentic type anti-GBM nephritis in rats. Abstract of 105th Annual Meeting of Pharmaceutical Society of Japan. Kanazawa, p. 166 (1985) (in Japanese)

13 Iso, T., Yamauchi, H., Suda, H., Nakata, K., Nishimura, K. and Iwao, J.: A new potent inhibitor of converting enzyme: (2R, 4R)-2-(2hydroxyphenyl) - 3-(3-mercaptopropionyl)-4thiazolidinecarboxylic acid (SA446), Japan. J. Pharmacol. 31, 875-882 (1981)

14 Brunner, H.R., Kirshman, J.D., Sealey, J.E. and Laragh, J.H.: Hypertension of renal origin: Evidence of two different mechanisms. Science 174, 1344-1346 (1971)

15 Swales, J.D., Thurston, H., Queiroz, F.P., Medina, A. and Holland, J.: Dual mechanism for experimental hypertension. Lancet 2, 1181-1184 (1971)

16 Glasser, R.J. and Michael, A.F.: Urinary kallikrein in experimental renal disease. Lab. Invest. 34, 616-622 (1976)

17 Naka, T., Ogihara, T., Hata, T., Maruyama, A., Mikami, H., Nakamura, O., Gotoh, S., Mauo, K., Ohde, $H$., Iwanaga, $K$. and Kumahara, $Y$.: The effect of aging on urinary kallikrein excretion in normotensive subjects and in patients with essential hypertension. J. Clin. Endocrinol. Metab. 52, 1023-1026 (1981)

18 Abe, K., Ito, T., Sato, M., Haruyama, T., Sato, K., Omata, K., Hiwatari, M., Sakurai, Y., Imai, Y. and Yoshinaga, K.: Role of prostaglandin in the antihypertensive mechanism of captopril in low renin hypertension. Clin. Sci. 59. Supp. $6141-$ $144(1980)$ 
19 Kondo, K., Kida, O., Kodama, K., Higa, T., Someya, N.r Morotomi, Y. and Tanaka, K.: Comparison of the acute effects of three structurally different converting enzyme inhibitors (captopril, SA-446 and MK-421) on blood pressure, the renin-angiotensin system and kallikrein-kinin system. Japan. J. Nephrol. 27, 317-342 (1985)
20 Vassali, P. and McCluskey, S.T.: The pathogenic role of the coagulation process in rabbit Masugi nephritis. Am. J. Pathol. 45, 653-677 (1964)

21 Humair, L., Potter, E.V. and Kwaan, H.C.: The role of fibrinogen in renal diseases. I. Production of experimental lesions in mice. J. Lab. Clin. Med. 74, 60-71 (1969) 